\title{
Buried adenocarcinoma hidden by normal squa- mous epithelium in Barrett's esophagus: should we enlarge the margins for endoscopic resections?
}

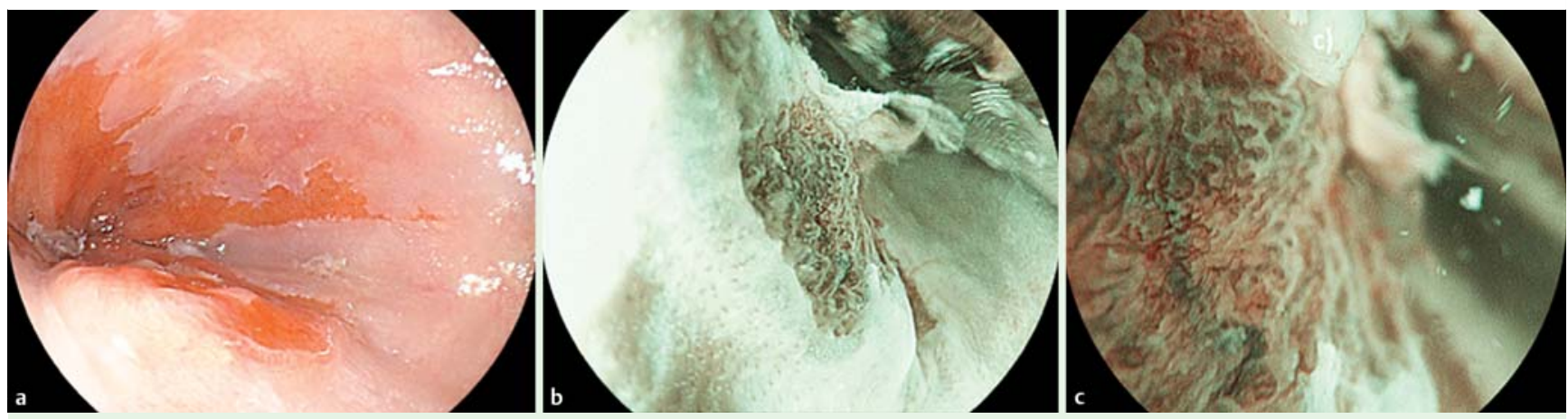

Fig. 1 Gastroscopy images with the Fujinon high-definition LASEREO system showing: a white mucosa, which corresponds to the normal squamous epithelium, and red mucosa, which corresponds to Barrett's esophagus, and the elevated suspect lesion on the left side of this; b, $\mathbf{c}$ on virtual chromoendoscopy, enhancement of the distinction between the columnar and squamous mucosa, along with the irregular architecture of glands with vascularization.

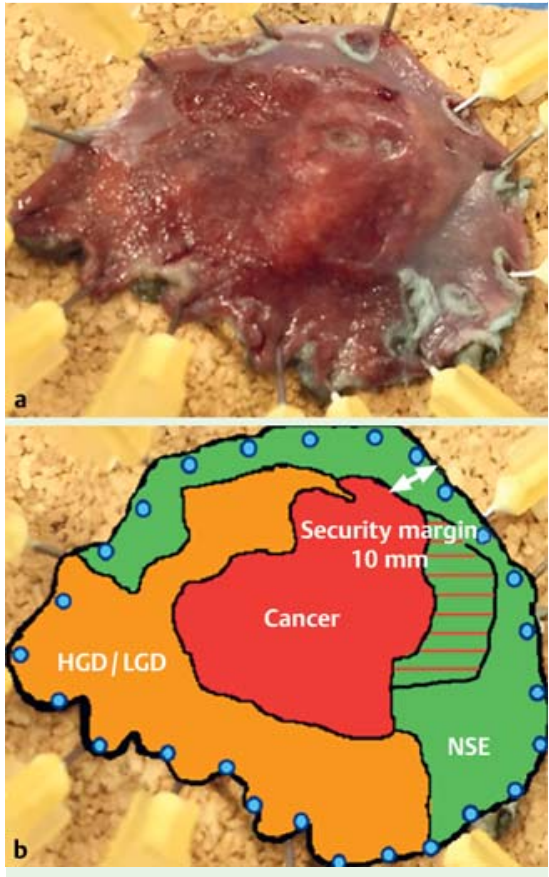

Fig. 2 The first specimen after fixation. a On the right side of the specimen, the lesion is elevated and covered by a normal squamous epithelium (NSE); $\mathbf{b}$ A schematic view of the specimen with a nodular ulcerated lesion (red) in the center; to the right of this, NSE (green) and buried adenocarcinoma covered by NSE (red - green); to the left, Barrett's esophagus with high grade dysplasia (HGD) and low grade dysplasia (LGD) (orange). Note: the blue dots that correspond to the coagulation dots giving a safety margin of $10 \mathrm{~mm}$ around the neoplastic area.
Endoscopic submucosal dissection (ESD) is an effective technique to resect neoplasia in Barrett's esophagus, including for lesions larger than $15 \mathrm{~mm}$ [1]. Nevertheless, in the area surrounding the Barrett's neoplasia, buried mucosa with various grades of dysplasia or adenocarcinoma can occur under normal squamous epithelium before or after treatment ( $0 \%$ $28 \%$ ) $[2,3]$. Buried components appear extremely difficult to detect endoscopically, which can result in the lesion size being underestimated [4]. Because of this invisible spread, we should enlarge our resection margins in order to avoid incomplete (R1) resections.

We report two cases of adenocarcinoma in Barrett's esophagus, with no history of previous treatment, which had buried components. Both lesions were carefully examined using white-light endoscopy and virtual chromoendoscopy to evaluate the pit and vascular patterns ( $\bullet$ Fig. 1 ). The edges were delineated with coagulation dots respecting a $10-\mathrm{mm}$ security margin, as previously suggested [5] ( $\mathrm{Fig} .2$ ). The two ESD specimens measured $35 \times 25 \mathrm{~mm}$ and $25 \times 28 \mathrm{~mm}$ after fixation.
The first lesion was a well-differentiated adenocarcinoma invading the submucosa to a depth of $150 \mu \mathrm{m}$ ( $\mathrm{sm} 1$ ). The distance between the deepest tumoral gland and the margin was over $500 \mu \mathrm{m}$. On the lateral oral edge, a 5-mm section of the adenocarcinoma was mostly buried and covered by normal squamous epithelium, but appeared slightly elevated endoscopically ( $\bullet$ Figs. 1,2). The lateral resection margin was composed of a normal squamous epithelium on the oral side ( $\bullet$ Fig.3) but showed high grade dysplasia on the anal side despite the 1-cm margin ( $\bullet$ Fig.4).

The second lesion was an adenocarcinoma invading the mucosa $(\mathrm{m} 2)$ with various buried components composed of intestinal metaplasia ( $\bullet$ Fig.5) but also high grade dysplasia and adenocarcinoma ( $\bullet$ Fig.6). The deep and lateral 1-cm margins were free of dysplasia.

To summarize, endoscopists must be aware of the potential of buried extension surrounding Barrett's neoplasia. This extension, with a normal superficial pattern, is very difficult to detect endoscopically. Therefore this justifies enlarging the security margins to more than $10 \mathrm{~mm}$ to achieve $\mathrm{R} 0$ resections.

Endoscopy_UCTN_Code_TTT_1AO_2AG

Competing interests: None 

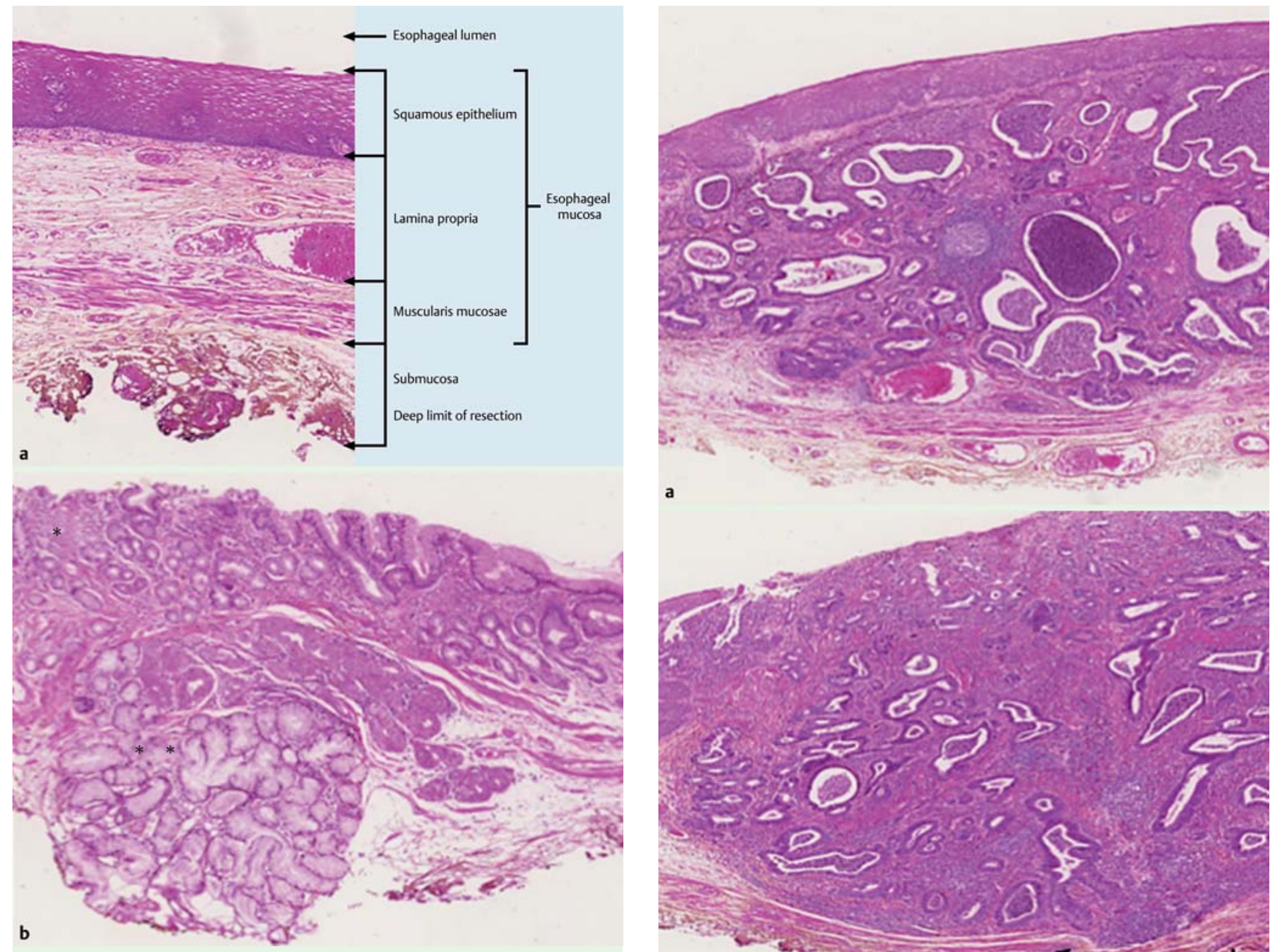

Fig. 3 Histological views of nondysplastic Barrett's esophagus showing: a normal esophageal mucosa and submucosa; b Barrett's esophagus without dysplasia $\left({ }^{*}\right)$ with normal esophageal glands $\left({ }^{* *}\right)$ beneath.

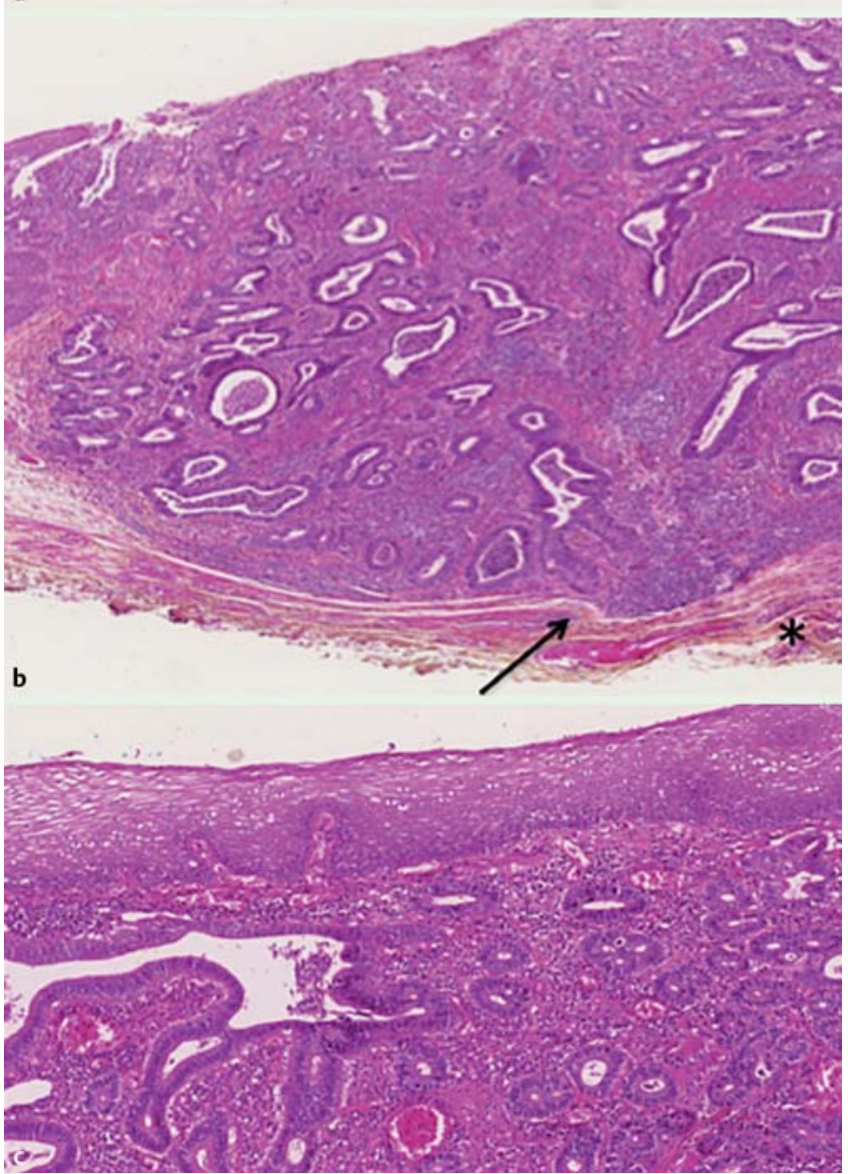

Fig. 4 Histology of the margins of the first specimen showing: a buried intramucosal well-differentiated adenocarcinoma, with glands containing intraluminal necrosis, and inflammatory stroma; b submucosal invasive carcinoma to $150 \mu \mathrm{m}$ (black arrow) but with deep resection margins that are free of disease $\left({ }^{*}\right)$; $\mathbf{c}$ buried adenocarcinoma beneath a normal squamous epithelium. 


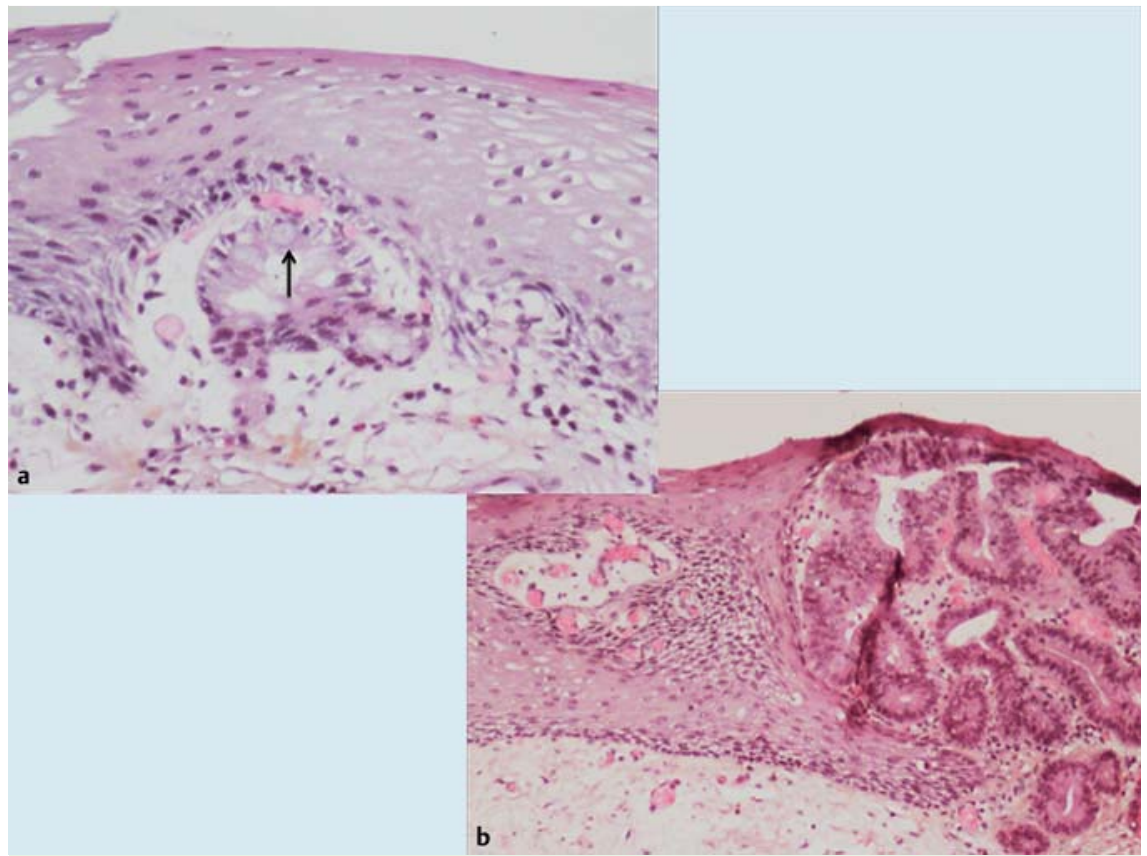

Fig. 5 Histology of the second buried specimen showing: a buried intestinal metaplasia with goblet cells (black arrow); $\mathbf{b}$ high grade dysplasia invading the normal squamous epithelium, which is covered by a thin layer of squamous cells.

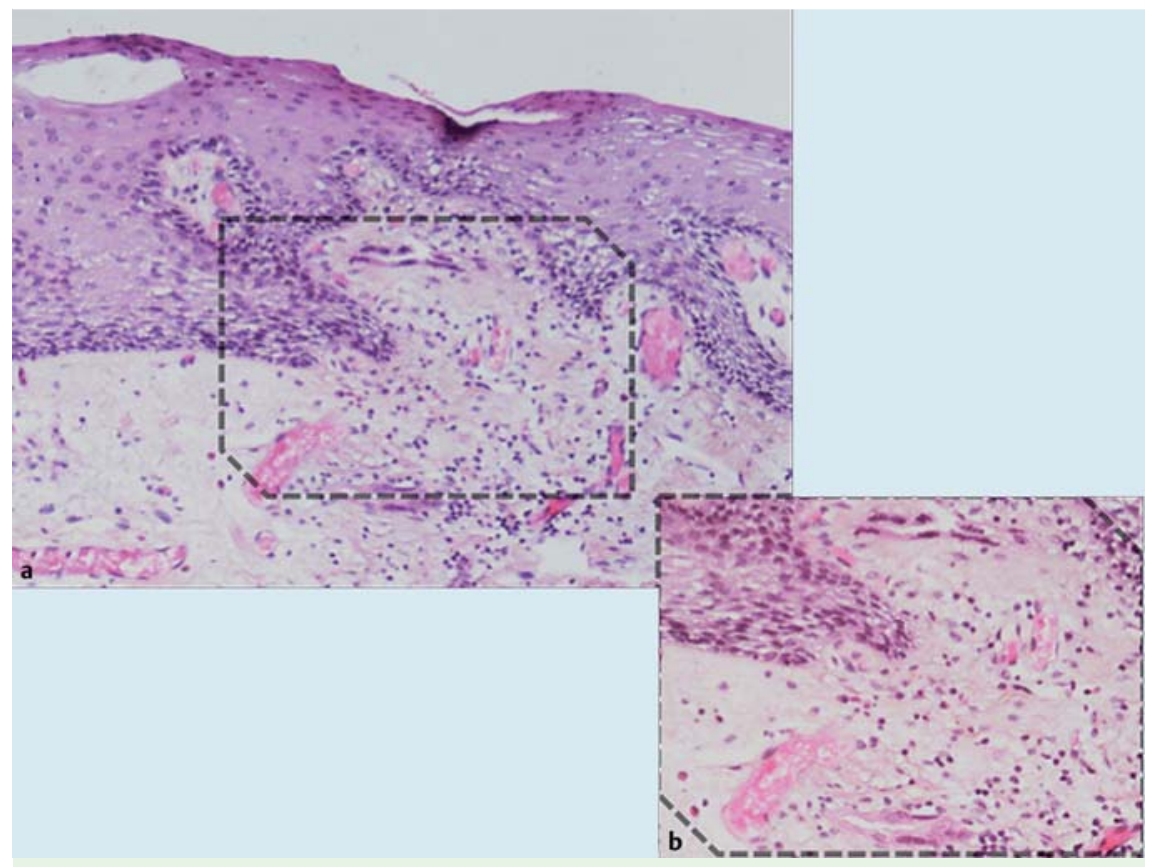

Fig. 6 Histology of the second buried adenocarcinoma showing: a intramucosal adenocarcinoma invading from underneath the squamous epithelium; $\mathbf{b}$ a higher magnification view of the mucincontaining adenocarcinoma.

\section{Domitille Erard-Poinsot ${ }^{1,2}$, Mathieu Pioche $^{1}$, Edouard Chabrun ${ }^{3}$, Jérôme Rivory $^{1}$, Geneviève Belleannee ${ }^{4}$, Valérie Hervieu², Thierry Ponchon}

${ }^{1}$ Department of Endoscopy and Gastroenterology, Pavillon L, Edouard Herriot Hospital, Lyon, France

${ }^{2}$ Department of Pathology, Edouard Herriot Hospital, Lyon, France

${ }^{3}$ Department of Endoscopy and Gastroenterology, Saint André Hospital,

Bordeaux, France

${ }^{4}$ Department of Pathology, Haut-Lévêque Hospital, Bordeaux, France

\section{References}

1 Chevaux JB, Piessevaux H, Jouret-Mourin A et al. Clinical outcome in patients treated with endoscopic submucosal dissection for superficial Barrett's neoplasia. Endoscopy 2015; 47: $103-112$

2 Chabrun E, Marty M, Zerbib F. Development of esophageal adenocarcinoma on buried glands following radiofrequency ablation for Barrett's esophagus. Endoscopy 2012; 44 (Suppl. 02): E392

3 Gray NA, Odze RD, Spechler SJ. Buried metaplasia after endoscopic ablation of Barrett's esophagus: a systematic review. Am J Gastroenterol 2011; 106: 1899-1908; quiz 1909

4 Omae M, Fujisaki J, Shimizu T et al. Magnifying endoscopy with narrow-band imaging findings in the diagnosis of Barrett's esophageal adenocarcinoma spreading below squamous epithelium. Dig Endosc Off J Jpn Gastroenterol Endosc Soc 2013; 25 (Suppl. 02): $162-167$

5 Chennat J, Ross AS, Konda VJA et al. Advanced pathology under squamous epithelium on initial EMR specimens in patients with Barrett's esophagus and high-grade dysplasia or intramucosal carcinoma: implications for surveillance and endotherapy management. Gastrointest Endosc 2009; 70: 417-421

\section{Bibliography}

DOI http://dx.doi.org/

10.1055/s-0034-1392675

Endoscopy 2015; 47: E439-E441

(c) Georg Thieme Verlag KG

Stuttgart · New York

ISSN 0013-726X

\section{Corresponding author} Mathieu Pioche, MD

Endoscopy unit - Digestive Disease department Pavillon L - Edouard Herriot Hospital 69437 Lyon

France

mathieu.pioche@chu-lyon.fr 